\title{
Thrombocytopenia according to Antiretroviral Drug Combinations, Viremia and CD4 Lymphocytes among HIV-Infected Patients in Cameroon A Snapshot from the City of Yaoundé
}

Alex Durand NKA ( $\sim$ nkaalexdurand@yahoo.com )

CIRCB https://orcid.org/0000-0002-9358-8661

Samuel Martin Sosso

CIRCB

Joseph Fokam

CIRCB

Bouba Yagai

CIRCB

Georges Teto

CIRCB

Rachel Kamgaing

CIRCB

Aline Tiga

CIRCB

Junie Yimga

CIRCB

Elias Nchiwan Nukenine

Faculty of Science University of Ngaoundere

Aubin Joseph Nanfack

CIRCB

Désiré Takou

CIRCB

Zélateur Aroga

Presbyterian Hospital of Ngaoundere

Vittorio Colizzi

University of Rome Tor Vergata

Alexis Ndjolo

CIRCB 
Research article

Keywords: HIV, thrombocytopenia, antiretroviral triple therapy, viral load, CD4, Cameroon

Posted Date: May 20th, 2019

DOI: https://doi.org/10.21203/rs.2.9478/v1

License: (c) (i) This work is licensed under a Creative Commons Attribution 4.0 International License. Read Full License

Version of Record: A version of this preprint was published at BMC Research Notes on September 26th, 2019. See the published version at https://doi.org/10.1186/s13104-019-4664-7. 


\section{Abstract}

Background Thrombocytopenia is an abnormal decrease in blood platelets, which can affect the prognosis of people living with HIV (PLHIV). In order to limit the occurrence of this haematological disorder, we evaluated the frequency of thrombocytopenia according to antiretroviral drug combinations, viremia and the immune status of PLHIV. Methods A cross-sectional and analytical study was conducted from June-November 2016 among 310 PLHIV at the "Chantal BIYA" International Reference Centre for research on HIV/AIDS prevention and management (CIRCB), Yaoundé, Cameroon. Thrombocytopenia was assessed by blood count on Mindray BC 3000 plus, then categorized as mild (50,000-149,999 platelets $/ \mu \mathrm{L})$, moderate $(20,000-49,999)$ and severe $<20,000 ; \mathrm{HIV}-1$ viremia was measured by Abbott m2000RT and CD4 by BD Facs Calibur; treatment history was retrieved from medical records. Data were analysed using Graph Pad Prism.6, with $\mathrm{p}<0.05$ considered statistically significant. Results Median age was 40 [IQR: 33-49] years with, and $60.9 \%$ of participants being female. Up to 79.0\% (245) were receiving antiretroviral therapy (ART); $54.5 \%$ had CD4 counts $<500$ cells $/ \mathrm{mm} 3$ and $25.4 \%$ had viremia $>3 \log 10$ $\mathrm{RNA} / \mathrm{ml}$. Overall rate of thrombocytopenia was $19.0 \%$ (59/310), with $17.4 \%$ (54/310) mild, $1.6 \%(5 / 310)$ moderate and $0.0 \%$ severe. Following ART-exposure, rate of thrombocytopenia was $64.6 \%(42 / 65)$ versus $6.9 \%(17 / 245)$ in naïve versus treated patients respectively, $p<0.0001$. Following ART regimens, rate of thrombocytopenia was $64.7 \%(11 / 17)$ versus $35.3 \%$ (6/17) among AZT-containing versus AZT-sparing regimens, $p=0.02$. Following viral load ranges, rate of thrombocytopenia was $15.8 \%(20 / 130)$ in those with undetectable viral load, $11.0 \%$ (12/101) with viral loads 1.60-3.0 log10 RNA/ml and 34.1\% (27/79) with viral loads $>3 \log 10 \mathrm{RNA} / \mathrm{ml}(\mathrm{p}=0.03 ; \mathrm{r}=-0.12)$. As concerns $\mathrm{CD} 4$-count, rate of thrombocytopenia was $16.2 \%$ (42/259) in those with $\geq 200 \mathrm{CD} 4 / \mathrm{mm} 3$ versus $33.3 \%(17 / 51)$ with $<200 \mathrm{CD} 4 / \mathrm{mm} 3$ $(p=0.0003 ; r=0.21)$. After adjusting for age, sex, ART, viral load and CD4, only ART exposure was significantly associated with decreased risk of thrombopenia $(p<0.0001)$. Conclusions Thrombocytopenia occurs generally at mild-level among PLHIV in Cameroon, especially among ART-naïve, AZT-treated, high viremia and severe immune-compromised patients. Interestingly, ART coverage appears as an independent factor in preventing the occurrence of thrombocytopenia, especially for AZT-sparing treatment combinations in countries with similar features like Cameroon.

\section{Background}

In Cameroon, an estimated 560,000 people were living with HIV (PLHIV) and 34,000 AIDS-associated deaths were reported in 2014[1]. Global efforts in improved healthcare services of PLHIV resulted in a significant decline in the number of HIV/AIDS-related deaths and new infections. Of note, the number of AIDS-related deaths has declined by 42\% worldwide between 2004 and 2014, with a greater decline in the sub-Saharan Africa region (48\%) [1].

Within the frame of the clinical monitoring of PLHIV, haematological abnormalities are most often observed in addition to other complications [2]. These abnormalities are most often characterized by a decrease in peripheral blood cells. Specifically, a deficit in peripheral blood cells is likely to impair the clinical outcomes through anaemia, neutropenia and thrombocytopenia [2]. 
Thrombocytopenia is a condition characterized by an abnormally low amount of platelets in the blood. In clinical practice, this refers to a number of platelets less than 150,000 per mm3 of blood [3]. In the context of HIV infection, events of thrombocytopenia are likely due to either the drug-induced adverse events or the infection itself [4]. In this prospect, thrombocytopenia would therefore be suggestive of an increase in viremia, an alteration of the immune system and could also be due to the type of antiretroviral therapy (ART) [4].

In the western world, monitoring of HIV-infected patients is focused on regular measurements of viral load and CD4 lymphocytes, and this approach is becoming gradually accessible in resource-limited settings (RLS), including sub-Saharan Africa (SSA) [5]. With limited evidence on possible correlations/associations between thrombocytopenia and reference monitoring approaches of ART in SSA settings, it becomes relevant to generate findings that would guide on the occurrence of thrombocytopenia following exposure or non-exposure to ART, following type of ARV drug combinations, and following the viral dynamics and immune status of patients in SSA countries [6].

The aim of our study was to assess the burden of thrombocytopenia according to antiretroviral therapy (ART), viremia and CD4-lymphocytes count of PLHIV.

\section{Methods}

\section{Study design and setting}

A cross-sectional and analytical study was carried out among PLHIV in Yaoundé, Cameroon, monitored at the "Chantal BIYA" International Reference Centre for research on HIV/AIDS prevention and management (CIRCB). The CIRCB is a government institute of the Ministry of Public Health, in charge of research and reference clinical monitoring of HIV-infected patients, with participation in external quality assurance programs for HIV screening/diagnosis, viral load measurements, CD 4 count, as well as biochemistry and haematological analysis (http://circb.cm/btc_circb/web/).

Following a consecutive sampling, a total of 310 participants were enrolled, based on the following criteria: (a) HIV-positive confirmed using the national algorithm in Cameroon; (b) providing of informed consent/assent for enrolment in the study; (c) documented treatment history. Non-inclusion was based on: events of pregnancy; co-infection with malaria; viral hepatitis B and C; or those who underwent blood transfusion during the past three months.

\section{Laboratory procedures}

At the medical units of CIRCB, the study information sheets were provided to each potential eligible patient and written informed consent/assent was obtaining from every participant. Sociodemographic data were obtained by data abstraction on a standard questionnaire for each participant. Clinical and therapeutic data were obtained from the medical records of each participant registered in the CIRCB database. 
Briefly, $4 \mathrm{~mL}$ of whole blood was collected in a dry tube (for serological analysis) and 2 tubes of $4 \mathrm{~mL}$ of whole blood were collected in Ethylène diamine tetra acetic acid (EDTA) containing-tubes. The serum obtained from blood in the dry tubes was immediately used for carrying out the serological tests (HIV, Hepatitis B and C) by solid phase immunochromatography. Centrifugation of one EDTA tube was performed to obtain plasma which was then separated in two (2) $700 \mu \mathrm{L}$ aliquots and stored at $-20^{\circ} \mathrm{C}$ before analysis for viral load by Real Time PCR on the ABBOTT m2000RT platform as per the manufacturer's instructions (www.abbottmolecular.com/products/infectious-diseases/realtime-pcr/hiv-1assay); the second EDTA tube was used to perform CD4 T lymphocyte typing using flow cytometry on Becton Dickinson's "FACS Calibur" according to the manufacturer's instructions (https://www.bdbiosciences.com/documents/BD_FACSCalibur_Brochure.pdf); the full blood count was performed on the "Mindray BC 3000 plus" automated system as per the manufacturer's instructions (https://www.mindray.com/en/product/BC-3000Plus.html) and the malaria diagnosis was done by fluorescence microscopy test as per the manufacturer's instructions (http://www.cyto.purdue.edu/cdroms/cyto10a/sponsors/media/partec/cyscope.pdf). The reliability and accuracy of the results were ensured by the systematic use of standard operational procedures and quality control panels.

Every potential case of thrombocytopenia from full blood count was confirmed by an observation of the blood smear. Thrombocytopenia was defined as a platelet count below $150 \times 103 / \mathrm{mm} 3$ [3], categorized as mild $(50,000-149,999$ platelets $/ \mu \mathrm{L})$, moderate $(20,000-49,999)$ and severe $<20,000$.

\section{Statistical analysis}

Data were recorded in an Excel spread sheet, and double-checked for data cleaning. The cleaned dataset was then analysed using the software Graph Pad prism version 6. The coefficient of correlation ( $r$ ) was used to determine the existing relationships between the quantitative variables using the Spearman algorithm. Categorical data were analysed using the Mann-Whitney $\mathrm{U}$ test; and the significance threshold for statistical tests was set at 0.05 .

\section{Results}

\section{Characteristics of the study population}

Out of 348 potential patients encountered, 29 had a positive plasmodium result and the remaining 09 had a positive viral hepatitis result (seven cases of hepatitis B and 2 cases of hepatitis $C$ ), which summed-up to 38 excluded cases. Thus, 310 patients were enrolled as study participants in the final dataset. Our study population consisted of 121 (39.03\%) males and 189 (60.96\%) females giving a female to male ratio of 2/1. Median age of participants was 40 [IQR: 33-49] years (Table 1). Regarding exposure to ART, 20.96\% (65/310) were ART-naïve and 79.03\% (245/310) were receiving ART as per national guidelines. Participants and by sex, viral load $\geq 3$ Log copies/ml were slightly more prevalent in men versus women: $29.75 \%(36 / 121)$ versus $23.28 \%(44 / 189)$ respectively, $p=0.20$ (Figure 3 ). 
The mean blood platelet count was $217.64 \pm 77.09$ and ranged from 34.000 to $466.000 / \mu \mathrm{L}$. The prevalence of thrombocytopenia was $19.03 \%$ (59/310) with a predominance of mild thrombocytopenia $17.42 \%(54 / 310)$, followed by $1.6 \%(5 / 310)$ moderate, and no case $(0.0 \%)$ of severe thrombocytopenia was found (Table 2).

\section{Thrombocytopenia according to sex}

According to sex, rate of thrombocytopenia was significantly higher among men as compared to women: $54.23 \%(32 / 59)$ versus $45.76 \%(27 / 59)$ respectively, $p=0.008$ (Figure 1 ).

\section{Thrombocytopenia according to age}

According to age distribution, the highest rate of thrombocytopenia was $59.32 \%$ (35/59) in adults aged between 19 to 45 years (Figure 2), without any significant difference $(p=0.39)$.

\section{Relationship between CD4 lymphocyte count and blood platelet count}

According to CD4 T lymphocytes, mild thrombocytopenia was $27.77 \%$ among those with severe immunodeficiency, with a statistically significant difference $(p=0.003)$ as compared to those with higher CD4 (Table 3). Furthermore, a weak positive and significant correlation was found between CD4 count and platelet count, $r=0.21$ (Figure 4).

\section{Relationship between HIV viral load and platelet count}

Up to $42.56 \%$ of thrombocytopenic patients were on viral load $>3 \log 10$, a significant higher burden as compared to those with low-level viremia, $p=0.037$ (Table 4). Furthermore, a weak negative correlation between platelet count and viral load; $r=-0.12$ (Figure 5).

\section{Relationship between ART-exposure and blood platelet count}

Among naïve PLHIV, $64.6 \%$ (42/65) of cases of thrombocytopenia were observed compared to $6.9 \%$ (17/245) in ARV treated patients. Interestingly, depending on ART regimen, 64.7\% (11/17) of thrombocytopenic patients were found among patients on AZT-containing HAART compared to $35.3 \%$ (6/17) non-AZT containing HAART, $p=0.02$ (Table 5).

\section{Multi-regression analysis}

After adjusting for age, sex, ART, viral load and CD4, only ART exposure was significantly associated with decreased risk of thrombocytopenia $(p<0.0001)$, as shown in table 6 .

\section{Discussion}


As the management of haematological disorders might be concerning in the course of HIV/AIDS, and for a better management of such potential burdens in settings here reference monitoring is restricted, it appears relevant to assess the burden of thrombocytopenia, to delineate possible determinants among PLHIV, and to propose measure to limiting the occurrence of this haematological disorder among PLHIV in countries like Cameroon.

Using the target population of PLHIV in the city of Yaounde, women appeared predominant $(60.96 \%)$, similar to the natural vulnerability to HIV and the epidemiological burden in the general population [6]. Our findings are therefore concordant to the study of Kouanfack et al., in 2010 and Essomba et al., in 2015 carried out in Cameroon (female predominance of $70.6 \%$ and $66.3 \%$ respectively) $[7,8]$. In the same line, the median age of 40 years is consistent with the sexually active population and the advent of ART that ensures longer lifespan to ART-experienced patients, as supported by Essomba et al. (43 years) [8].

In this target population of chronically infected Cameroonians, $19.03 \%$ of subjects had thrombocytopenia, almost all being mild disorders. Of note, the absence of severe thrombocytopenia can be explained by the fact that most of the patients were monitored within their routine care as outpatient, without emergency and most (79.0\%) of them were on treatment against HIV infection, as appropriate ART also contribute in limiting event of thrombocytopenia [14]. The rate of thrombocytopenia slightly differs to reports from Tene et al. (13.67\% in 2014 within the same city) [9]. The slight difference could be attributed lower representativeness in the previous study ( $n=139$ participants). On the other hand, our observation is close to that obtained by Taremwa et al., in southwestern Uganda in 2015 (17.4\%) [10] and $20 \%$ by Alaei et al., in Iran around the year 2000 [11].

According to the distribution of thrombocytopenic cases by sex, men are more affected than women, as per knowledge on the variation of blood platelets by sex[12]. This observation could also be affected by the higher frequency of virological failure among men (29.75\%) compared to women $(23.28 \%)$ in our study thereby altering, if any effect, the platelet pipeline with high-level viremia [13].

Regarding the distribution of blood platelet count according to age, it has been found that platelet levels are low in children, high in adults and low in the elderly populations [13]. In our study population, adults had a higher thrombocytopenia rate (59.32\% in people aged 19 to 45 years old) than children $(3.38 \%)$ and the elderly (3.38\%). This interpretation is limited by the low rate of children and elderly populations, which calls for investigation in this target population. Severely immune-compromised patients had $29 \%$ thrombocytopenia, with a significantly weak positive correlation between blood platelet count and CD4 count. This implies that decreasing CD4 cell count may be accompanied by a decrease in blood platelet count, similar to findings by Taremwa et al., in Uganda [10]. On the same line, almost half (45.76\%) of patients with high-level viremia ( $\geq 3 \log 10$ copies $/ \mathrm{ml}$ ) were thrombocytopenic, indicating a significantly weak negative correlation between blood platelet count and plasma viral load. This may be attributed to the fact that an increase in viral activity could be accompanied by a decrease in blood platelet count, and consistent with the data of O'Bryan et al. in the United States [14]. As also reported by Mbanya et al., in 
2002, HIV infection can cause thrombocytopenia by various mechanisms including bone marrow destruction induced by viral activity, ART or immunological factors [15].

In our study, about $9 \%$ of people on ART had thrombocytopenia, slightly less than $13 \%$ obtained in Uganda [10], and higher than the $4.1 \%$ found in Ethiopia [17]. This suggest that ART might have a protective effect against thrombocytopenia, especially for those treated with AZT-sparring regimens (due to anaemic adverse effect of AZT) [18]. Among ART-naïve individuals, the burden of thrombocytopenia (37\%) was slightly lower (27\%) than data reported at the Yaoundé teaching Hospital (in the same township). O'Bryan et al., in the United States also showed a decreased rate of thrombocytopenia in an HIV infected population moving from the pre-therapeutic to per-ART phase [14]. Of great clinical relevance, after adjusting for age, sex, ART, viral load and CD4, only ART exposure was significantly associated with decreased risk of thrombocytopenia. This result justifies the significance implication of ART in preventing risks of thrombocytopenia [19].

In assessing thrombocytopenia, we could not evaluate the root cause of platelet deficiency as either being of peripheral or central origin; also, our assessment is less representative of people at extreme age, thus calling for further investigations on haematological disorders in these target populations.

\section{Conclusion}

In this main city of the Centre Region of Cameroon, thrombocytopenia affects less than a quarter of PLHIV, with the majority having only mild thrombocytopenia. Thrombocytopenia occurs especially among ART-naïve patients, AZT-containing regimens, and slightly in the event of high-level viremia and severe immunodeficiency. Of great clinical relevance, after adjustment, ART coverage appears as an independent factor in preventing the occurrence of thrombocytopenia. However, an alternate therapeutic approach is needed for AZT-sparing treatment combinations in countries with similar features like Cameroon.

\section{List Of Abbreviations}

ARV: Antiretroviral;

AIDS: Acquired immunodeficiency syndrome;

ART: Antiretroviral therapy;

AZT: zidovudine;

CD4: Cluster of differentiation;

CHU: University Health Centre.

CIRCB: "Chantal BIYA" International Reference Centre for research on HIV/AIDS prevention and management 
HAART: Highly active antiretroviral therapy

HIV: Human Immunodeficiency Virus;

PLHIV: People living with HIV;

\section{Declarations}

\section{Ethics approval and consent to participate}

This study obtained an ethical clearance from the Institutional Review Board of the University of Douala ( $\mathrm{N}^{\circ} \mathrm{CEI}-\mathrm{UD} / 544 / 04 / 2016 / \mathrm{T}$ ) and an administrative authorization from the CIRCB Directorate General. The participants freely provided their written informed consent forms, either in French or English language (with respect to the first language of the participant), while the minor participants provided their assent. For each participants aged<16years, a written informed consent was obtained for parent or legal guardian, after providing of the study information. For purpose of confidentiality, data were processed by using specific identifiers and saved by a password encrypted computer.

\section{Consent to publish}

Not applicable

\section{Disclosure statement}

Authors declare that they have no financial, personal, or professional interests that could be construed to have influenced this manuscript.

\section{Availability of data and materials}

All datasets on which the conclusions of the manuscript are drawn are duly presented in the main paper and supplemental files.

\section{Competing interests}

Authors have no potential conflict or competing interests to declare.

\section{Funding}

The present study technically and financially supported by the CIRCB, under annual budget of 2016 . The CIRCB made available for this study the financial and material resources such as reagents, laboratory consumables and access to the various platforms for carrying out the biological analyses of the samples; the expertise of its staff in the areas of clinical data collection, analysis of samples and data has been heavily involved.

\section{Authors' contributions}


Conceived the study: Alex Durand Nka; Samuel Martin Sosso; Joseph Fokam; Elias Nchiwan Nukenine; Zélateur Aroga; Vittorio Colizzi; Alexis Ndjolo.

Collected the data: Alex Durand Nka; AlineTiga ; Bouba Yagai ; Rachel Kamgaing Simo; Junie Flores Yimga.

Analysed the data: Alex Durand Nka; Bouba Yagai ; Joseph Fokam; Elias Nchiwan Nukenine;

Initiated the manuscript: Alex Durand Nka; Samuel Martin Sosso; Joseph Fokam; Bouba Yagai ; Georges Teto.

Revised the manuscript: Alex Durand Nka; Samuel Martin Sosso; Joseph Fokam; Rachel Kamgaing Simo, Bouba Yagai ; Georges Teto; Elias Nchiwan Nukenine ; Zélateur Aroga; Vittorio Colizzi; Alexis Ndjolo.

Approved the final version of the submitted manuscript: All the authors.

Acknowledgements

We thank the Department of Biomedical Sciences of the Faculty of Sciences of the University of Ngaoundéré and the "Chantal BIYA" International Reference Center

\section{References}

1. AIDS_by_the_numbers_2015_fr.pdf [Internet]. [cited 18 sept 2018]. Avalable on : http://www.unaids.org/sites/default/files/media_asset/AIDS_by_the_numbers_2015_fr.pdf

2. Wankah PN, Tagny CT, Mbanya DNS. Profile of blood cell abnormalities among antiretroviral therapy naiive HIV patients attending the Yaounde University Teaching Hospital, Cameroon. BMC Hematol [Internet]. 8 sept 2014 [cited 18 sept 2018];14. Avalable on : https://www.ncbi.nlm.nih.gov/pmc/articles/PMC4164737/

3. Giles C. The platelet count and mean platelet volume. Br J Haematol. mai 1981;48(1):31-7.

4. Thrombocytopenia (low platelet count) - Symptoms and causes [Internet]. Mayo Clinic. [cited 16 oct 2018]. Avalable on : http://www.mayoclinic.org/diseases-conditions/thrombocytopenia/symptomscauses/syc-20378293

5. Viral load testing capacity still weak in sub-Saharan Africa, 7-country study finds [Internet]. [Cited 3 oct 2018]. Avalable on : http://www.aidsmap.com/Viral-load-testing-capacity-still-weak-in-sub-SaharanAfrica-7-country-study-finds/page/3107907

6. Morrison SJ, Uchida N, Weissman IL. The biology of hematopoietic stem cells. Annu Rev Cell Dev Biol. 1995;11:35-71. 
7. Kouanfack C, Laborde-Balen G, Aghokeng AF, Bourgeois A, Dontsop M, Mben J-M, et al. WHO clinical criteria-based initiation of antiretroviral therapy: lessons from rural district hospitals in Cameroon with regard to 2009 revised WHO recommendations. Trop Med Int Health TM IH. mai 2010;15(5):580-3.

8. Essomba NE, Mbatchou Ngahane BH, Nida M, Temfack E, Mapoure Njankouo Y, Abeng RL, et al. Profil clinique et immunologique des patients infectés par le VIH à l'initiation du traitement antirétroviral à Douala. Bull Société Pathol Exot. oct 2015;108(4):255-61.

9. Tene L, Tagny CT, Mintya-Ndoumba A, Fossi VN, Mbanya D. Haemostatic trends in HIV-infected individuals in Yaoundé, Cameroon: a pilot study. Blood Coagul Fibrinolysis Int J Haemost Thromb. juill 2014;25(5):422-5.

10. Taremwa IM, Muyindike WR, Muwanguzi E, Boum Y, Natukunda B. Prevalence of HIV-related thrombocytopenia among clients at Mbarara Regional Referral Hospital, Mbarara, southwestern Uganda. J Blood Med. 2015;6:109-13.

11. Alaei $K$, Alaei A, Mansoori D. Thrombocytopenia in HIV-infected patients, Islamic Republic of Iran. East Mediterr Health J Rev Sante Mediterr Orient Al-Majallah Al-Sihhiyah Li-Sharq Al-Mutawassit. nov 2002;8(6):758-64.

12. Stevens RF, Alexander MK. A sex difference in the platelet count. $\mathrm{Br} \mathrm{J}$ Haematol. oct 1977;37(2):295-300.

13. Segal JB, Moliterno AR. Platelet counts differ by sex, ethnicity, and age in the United States. Ann Epidemiol. févr 2006;16(2):123-30.

14. O'Bryan TA, Okulicz JF, Bradley WP, Ganesan A, Wang X, Agan BK. Impact of the highly active antiretroviral therapy era on the epidemiology of primary HIV-associated thrombocytopenia. BMC Res Notes [Internet]. 23 oct 2015 [cited 16 oct 2018];8. Avalable on :

https://www.ncbi.nlm.nih.gov/pmc/articles/PMC4619221/

15. Oksenhendler E, Seligmann M. HIV-related thrombocytopenia. Immunodefic Rev. 1990;2(3):221-31.

16. Mbanya D, Tapko J-B, Azowe F, Kaptue L. [Aetiologic factors and clinical features associated with thrombocytopenia in Cameroonese adults: the importance of Plasmodium falciparum malaria]. Sante Montrouge Fr. sept 2002;12(3):331-5.

17. Wondimeneh Y, Muluye D, Ferede G. Prevalence and associated factors of thrombocytopenia among HAART-naive HIV-positive patients at Gondar University Hospital, northwest Ethiopia. BMC Res Notes. 6 janv 2014;7:5.

18. Scaradavou A. HIV-related thrombocytopenia. Blood Rev. mars 2002;16(1):73-6. 
19. Keith Henry MD. Risk for HIV-Related Thrombocytopenia Plunges in the Combination ART Era. NEJM J Watch [Internet]. 19 nov 2014 [cité 15 avr 2019];2014. Avalable on :

https://www.jwatch.org/NA36334/2014/11/19/risk-hiv-related-thrombocytopenia-plunges-combinationart

\section{Tables}

Table 1: Socio-demographic data

\begin{tabular}{ccc}
\hline Variables & Frequency & Percentage (\%) \\
\hline Sex & & \\
Male & 121 & 39,03 \\
Female & 189 & 60,96 \\
Age in years & & \\
$0-12$ & 17 & 5,48 \\
$13-18$ & 11 & 3,54 \\
$19-45$ & 175 & 56,45 \\
$45-60$ & 86 & 27,74 \\
$>60$ & 21 & 6,77 \\
Total & 310 & 100 \\
\hline
\end{tabular}

Table 2: Distribution of Blood platelet count in PLHIV

\begin{tabular}{ccccc}
\hline Blood platelet count $(/ \mu \mathrm{L})$ & Frequency & Mean \pm STD & Percentage (\%) \\
\hline Severe thrombocytopenia $<20,000$ & 0 & 0 & 0 \\
Moderate thrombocytopenia $(20000-50000)$ & 5 & $37.6 \pm 3.7$ & 1.61 \\
\hline Mild Thrombocytopenia $(50000-150000)$ & 54 & $119.3 \pm 25.0$ & 17.42 \\
\hline Normal platelet count $(150000-450000)$ & 250 & $241.4 \pm 60.6$ & 80.65 \\
\hline Thrombocytosis $>450000$ & 1 & 466 & 0.32 \\
\hline
\end{tabular}

STD: standard deviation

Table 3: Distribution of blood platelet count according to CD4 lymphocyte count 


\begin{tabular}{|c|c|c|c|c|c|}
\hline 3lood platelet count $(/ \mu \mathrm{L})$ & & $\begin{array}{l}\text { CD4 lymphocyte } \\
\text { count }\end{array}$ & & & \\
\hline & $<200$ & {$[200-300]$} & {$[300-500]$} & $>500$ & Total \\
\hline thrombocytopenia $<20,000$ & $0(0 \%)$ & $0(0 \%)$ & $0(0 \%)$ & $0(0 \%)$ & $0(0 \%)$ \\
\hline $\begin{array}{l}\text { tte thrombocytopenia ( } 20000 \\
\text { l) }\end{array}$ & $2(40 \%)$ & $1(20 \%)$ & $1(20 \%)$ & $1(20 \%)$ & $5(100 \%)$ \\
\hline $\begin{array}{l}\text { hrombocytopenia (50000 } \\
\text { 0) }\end{array}$ & 15(27.77\%) & $5(9.25 \%)$ & $13(24.07 \%)$ & $21(38.88 \%)$ & $54(100 \%)$ \\
\hline $\begin{array}{l}\text { I platelet count (150000 - } \\
\text { l) }\end{array}$ & $34(13.60 \%)$ & 30 (12.00\%) & $68(27.70 \%)$ & $118(47.2 \%)$ & $250(100 \%)$ \\
\hline Jocytosis> 450000 & $0(0 \%)$ & $0(0 \%)$ & $0(0 \%)$ & $1(100 \%)$ & $1(100 \%)$ \\
\hline
\end{tabular}

Table 4: Distribution of blood platelet count by plasma viral load levels

\begin{tabular}{lcccc}
\hline Blood platelet count $(/ \mu \mathrm{L})$ & \multicolumn{3}{c}{ Plasma viral load } \\
\hline & Not Detectable & $1.60 \log _{10}-3.00 \log 10$ & $>3,00 \log 10$ & Total \\
\hline Severe thrombocytopenia & $0(0 \%)$ & $0(0 \%)$ & $0(0 \%)$ & $0(0 \%)$ \\
\hline Moderate thrombocytopenia & $1(20 \%)$ & $0(0 \%)$ & $4(80 \%)$ & $5(100 \%)$ \\
\hline Mild thrombocytopenia & $19(35.18 \%)$ & $12(22.22 \%)$ & $23(42.59 \%)$ & $54(100 \%)$ \\
\hline Normal platelet count & $110(44 \%)$ & $88(35.2 \%)$ & $52(20.8 \%)$ & $250(100 \%)$ \\
Thrombocytosis & $0(0 \%)$ & $1(100 \%)$ & $0(0 \%)$ & $1(100 \%)$
\end{tabular}

\begin{tabular}{ccc}
\hline ART & Total(n) & Frequency (\%) \\
\hline Treatment with AZT & 11 & 64.7 \\
Treatment without AZT & 6 & 35.3 \\
& $\mathrm{p}=0.02$ & \\
\hline
\end{tabular}

Table 5: repartition between ARV treatment and blood platelet count.

Thrombocytopenic cases on ART were more represented in those who were in therapeutic combinations containing AZT.

Table 6: Regression analysis of thrombocytopenia 


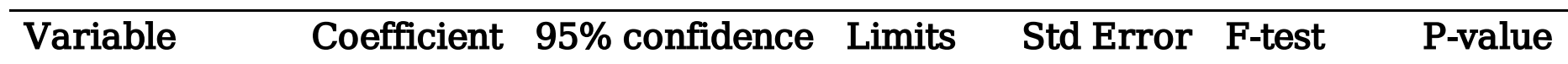

\begin{tabular}{lllllll}
\hline Age & -0.297 & -0.805 & 0.211 & 0.258 & 1.3223 & 0.251083 \\
\hline Sex (F/M) & -3.495 & -18.428 & 11.438 & 7.589 & 0.2121 & 0.645447 \\
\hline CD4 & 0.014 & -0.011 & 0.038 & 0.012 & 1.2325 & 0.267801 \\
\hline Viral Load & 0.000 & 0.000 & 0.000 & 0.000 & 1.5098 & 0.220118 \\
\hline $\begin{array}{l}\text { ART Exposure } \\
\text { (Naive/ART) }\end{array}$ & -114.561 & -136.604 & -92.519 & 11.201 & 104.5991 & $<0.000001$ \\
\hline Constant & 241.360 & 215.514 & 267.206 & 13.135 & 337.6706 & $<0.000001$ \\
\hline
\end{tabular}

After adjusting for age, sex, ART, viral load and CD4, only ART exposure was significantly associated with decreased risk of thrombocytopenia $(P<0.0001)$.

\section{Figures}




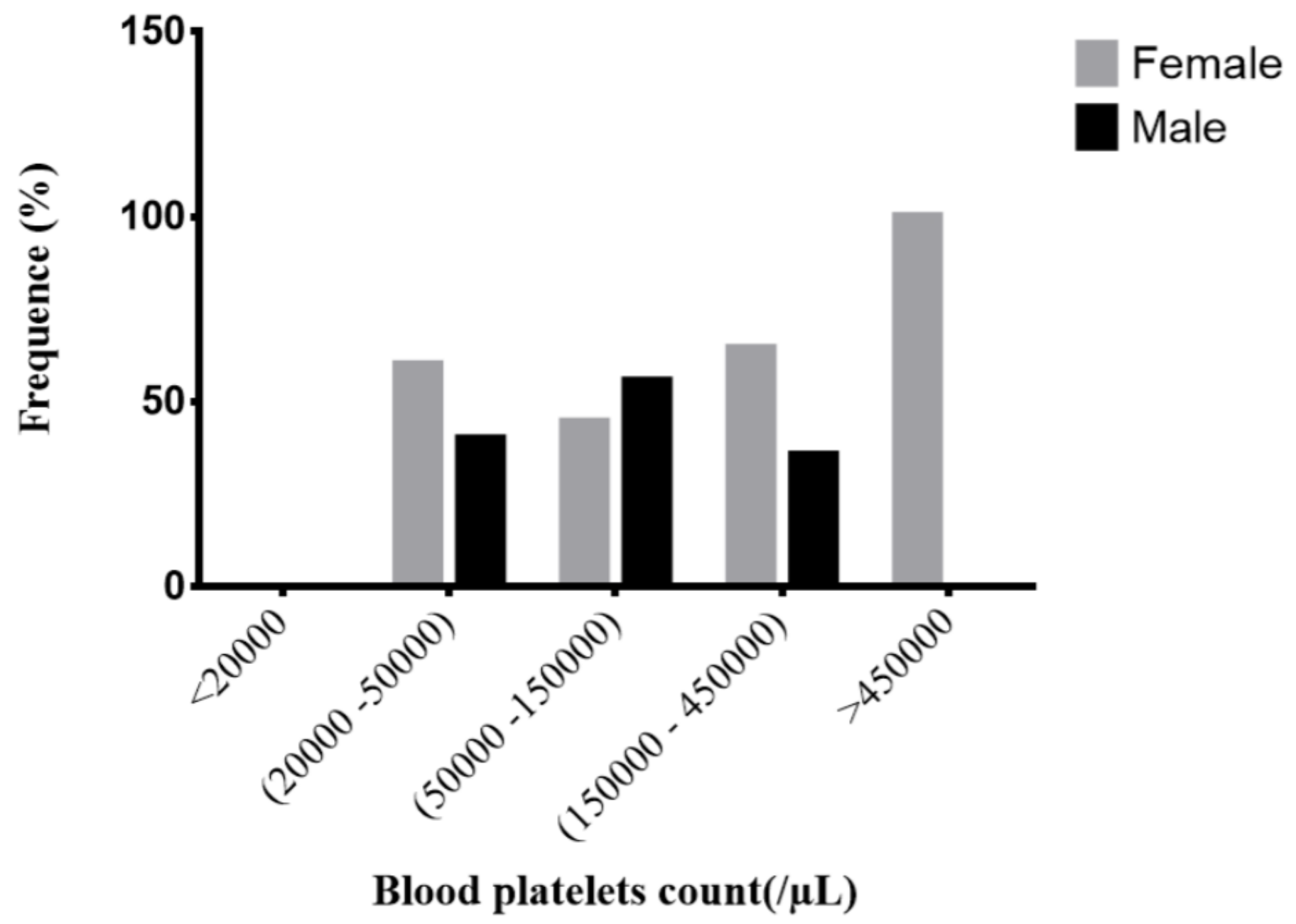

Figure 1

Distribution of blood platelets count by Sex 

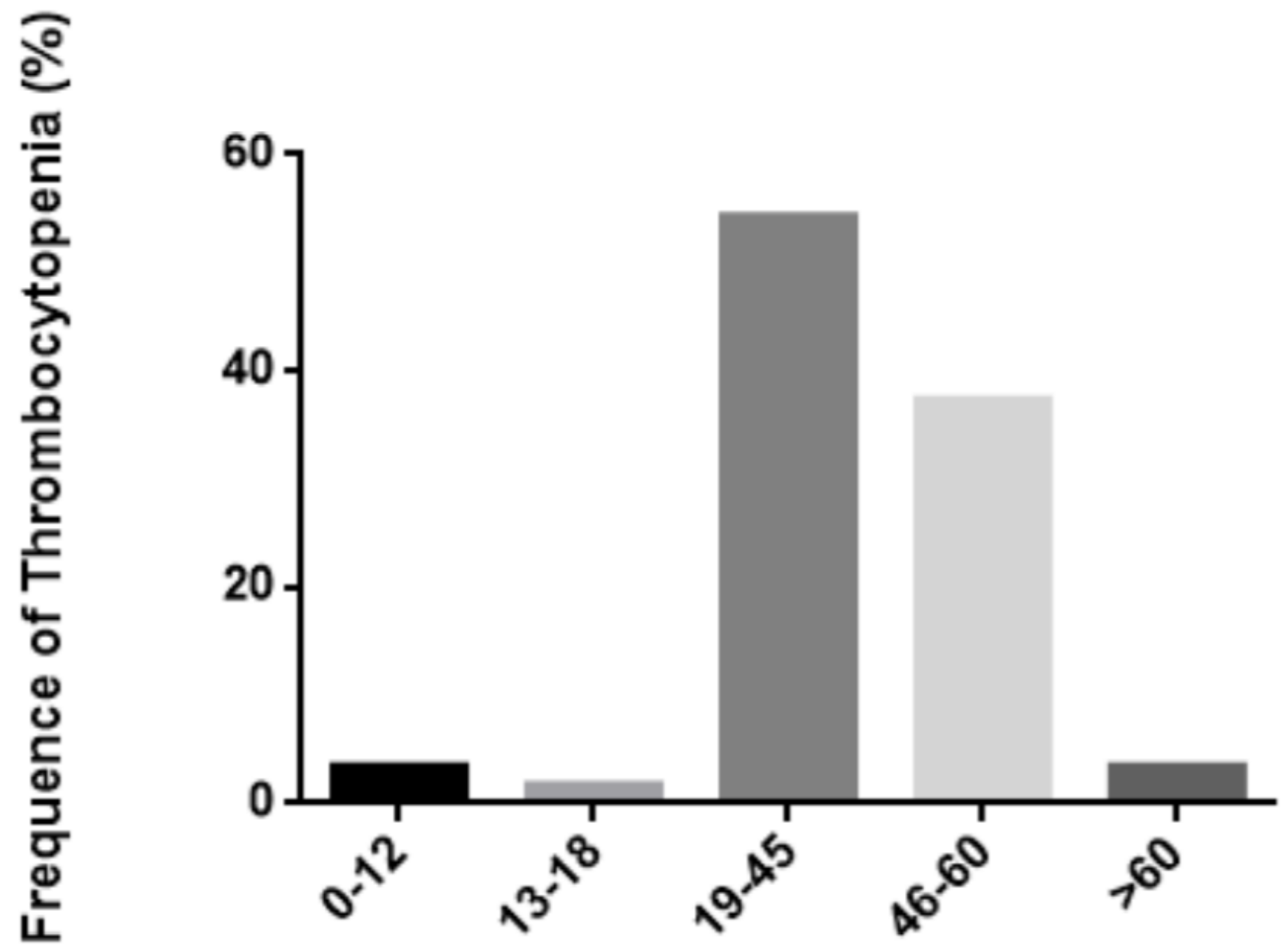

Age ranges (Years)

Figure 2

Distribution of blood platelet count by Age 


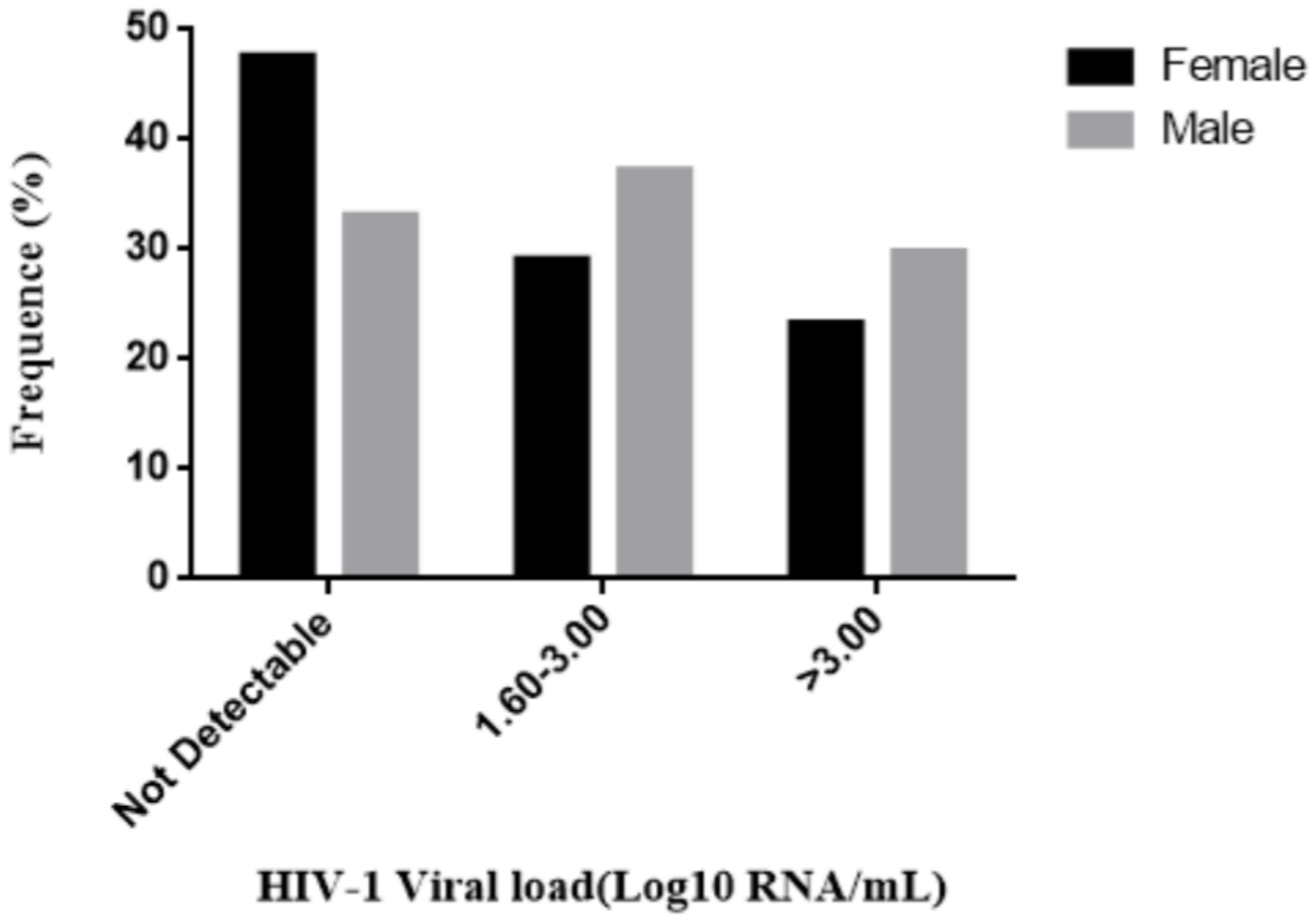

Figure 3

Distribution of HIV viral load by Sex 


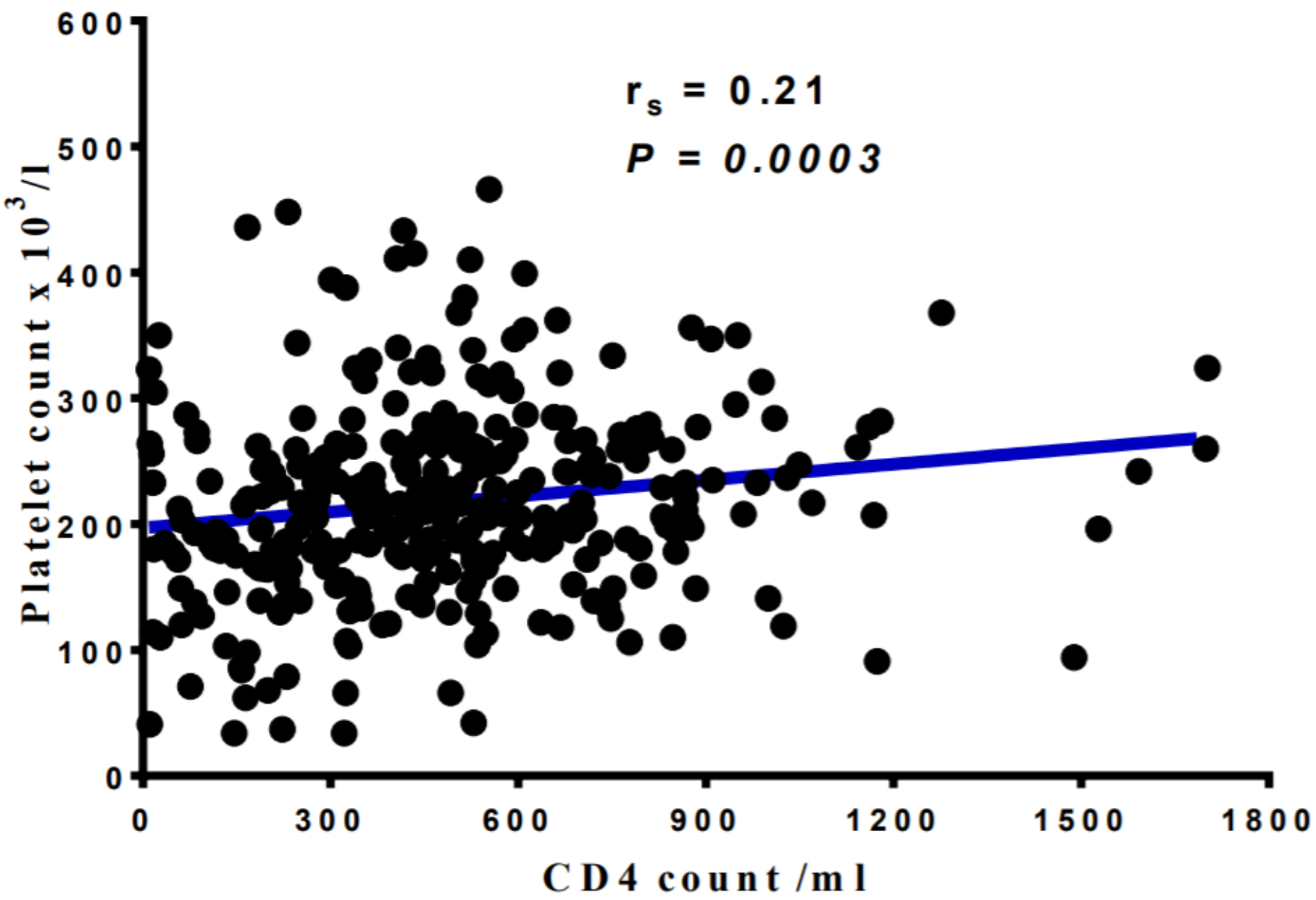

Figure 4

Correlation between blood platelet count and level of TCD4 lymphocytes. CD4: Cluster of differenciation 4. 


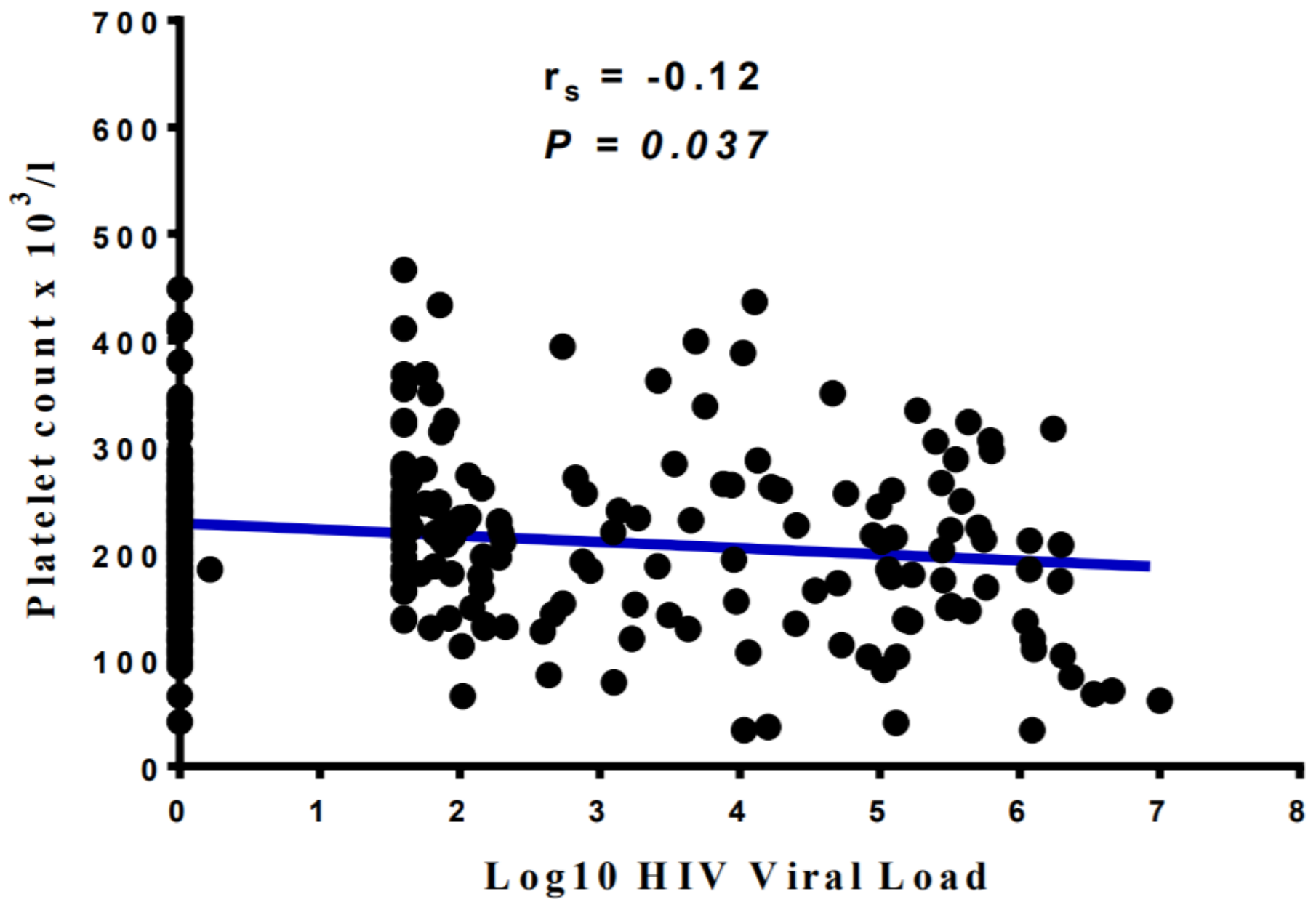

Figure 5

Correlation between blood platelet count and HIV viral load. HIV: Human immunodeficiency virus 